University of Montana

ScholarWorks at University of Montana

2-1993

\title{
Transcriptional Analyses and Mapping of the ospC Gene in Lyme Disease Spirochetes
}

\author{
Richard T. Marconi \\ Rocky Mountain Laboratories - NIAID \\ D. Scott Samuels \\ University of Montana - Missoula, scott.samuels@umontana.edu \\ Claude F. Garon \\ Rocky Mountain Laboratories - NIAID
}

Follow this and additional works at: https://scholarworks.umt.edu/biosci_pubs

Part of the Biology Commons

Let us know how access to this document benefits you.

\section{Recommended Citation}

Marconi, Richard T.; Samuels, D. Scott; and Garon, Claude F., "Transcriptional Analyses and Mapping of the ospC Gene in Lyme Disease Spirochetes" (1993). Biological Sciences Faculty Publications. 325.

https://scholarworks.umt.edu/biosci_pubs/325

This Article is brought to you for free and open access by the Biological Sciences at ScholarWorks at University of Montana. It has been accepted for inclusion in Biological Sciences Faculty Publications by an authorized administrator of ScholarWorks at University of Montana. For more information, please contact scholarworks@mso.umt.edu. 


\section{Journal of Bacteriology \\ Transcriptional analyses and mapping of the ospC gene in Lyme disease spirochetes. \\ R T Marconi, D S Samuels and C F Garon J. Bacteriol. 1993, 175(4):926.}

Updated information and services can be found at:

http://jb.asm.org/content/175/4/926

These include:

CONTENT ALERTS Receive: RSS Feeds, eTOCs, free email alerts (when new articles cite this article), more» 


\title{
Transcriptional Analyses and Mapping of the $\operatorname{osp} C$ Gene in Lyme Disease Spirochetes
}

\author{
RICHARD T. MARCONI, ${ }^{*}$ D. SCOTT SAMUELS, AND CLAUDE F. GARON \\ Laboratory of Vectors and Pathogens, Rocky Mountain Laboratories, National Institute \\ of Allergy and Infectious Diseases, Hamilton, Montana 59840
}

Received 6 October 1992/Accepted 1 December 1992

\begin{abstract}
In Lyme disease spirochetes, the ospC gene encodes a 22.7-kDa protein referred to as either the pC or the OspC protein. Using a variety of electrophoretic approaches followed by Southern blotting and probing with oligonucleotide probes, we mapped the osp $C$ gene to a circular 26-kb plasmid. The ospC gene represents the first gene to be mapped to a circular plasmid in Lyme disease spirochetes. The occurrence of this gene in isolates belonging to each of the three Lyme disease-associated species, Borrelia burgdorferi, Borrelia garinii, and the VS461 group, was evaluated. The osp $C$ gene was found to occur in all 21 isolates tested from each of the three species. Differential hybridization with a series of osp $C$ probes in both Northern (RNA) and Southern blot analyses demonstrated that there is sequence variability in the $\operatorname{osp} C$ gene among isolates. While the gene was found to be present in all isolates, not all actively transcribed the gene. Transcriptional start site analyses suggest that the gene may be under the control of multiple promoters that are highly similar in nucleotide sequence.
\end{abstract}

The organization of the genetic material among members of the genus Borrelia is unusual among eubacteria in that the genetic material is distributed between a linear chromosome and a series of both linear and circular plasmids $(4,5,10)$. Although variable, Borrelia plasmids account for a significant fraction of the total genetic material. In Lyme disease borreliae, all genes mapped to date have been found to reside on either the $1,000-\mathrm{kb}$ linear chromosome $(12,28)$ or, in the case of the $\operatorname{ssp} A B$ operon, on a linear plasmid $(5,6,8)$ that ranges in size from approximately 49 to $59 \mathrm{~kb}(4,5,13,23)$. In general, the coding capacity of the plasmids remains largely undefined. It seems likely that in addition to $\operatorname{osp} A B$, other genes will also be mapped to plasmids.

Recently, a third outer surface protein (OspC) in Lyme disease spirochetes was identified, and its gene was sequenced (11). The physiological role or pathological significance of OspC has not yet been defined. Although somewhat variable among isolates, the molecular mass of OspC is approximately $22.7 \mathrm{kDa}$. OspC appears distinct from the 22-kDa proteins described by Luft et al. (14) and Simpson et al. (26). The level of expression of OspC has also been found to vary among isolates. Wilske et al. reported that OspC is expressed as a major protein in approximately $45 \%$ of European isolates and only rarely in North American isolates (31). For the three spirochete species, Borrelia burgdorferi, Borrelia garinii, and group VS461, known to be associated with Lyme disease $(2,15-17,19,29)$, the presence, degree of conservation, and map location of the $o s p C$ gene have not yet been addressed.

In this study, we have mapped the location of the ospC gene, determined its transcriptional start site(s), and compared the expression of the gene among isolates of Lyme disease spirochetes. The results presented here demonstrate that the $\operatorname{osp} C$ gene is carried on a $26-\mathrm{kb}$ circular plasmid. The ospC gene represents the first Borrelia gene to be mapped to a circular plasmid. Transcriptional start site analyses have revealed that the control region of the gene is similar among

\footnotetext{
${ }^{*}$ Corresponding author.
}

isolates of Lyme disease spirochetes and that the gene may be under the control of multiple promoters. Northern (RNA) blot analysis has also demonstrated that the transcriptional expression of the $\operatorname{ssp} C$ gene varies among isolates.

\section{MATERIALS AND METHODS}

Cultivation of Borrelia isolates. The isolates investigated in this study are described in Table 1 . All isolates were previously identified to the species level by $16 \mathrm{~S}$ rRNA sequence analysis $(1,16,17)$, through the use of $16 \mathrm{~S}$ rRNA-directed species-specific oligonucleotide probes (19) or polymerase chain reaction primer sets (15), by DNA-DNA hybridization $(2,20)$, or by multilocus enzyme electrophoresis $(9)$. The species nomenclature used in this paper is that proposed by Baranton et al. (2). Bacterial isolates were cultivated in BSKII medium at $34^{\circ} \mathrm{C} \mathrm{(3)}$, harvested by centrifugation, and washed twice with phosphate-buffered saline prior to use in subsequent experiments.

Southern blot analysis of the osp $C$ gene. DNA was isolated as previously described (7). Whole-cell DNA was fractionated by electrophoresis in $0.35 \%$ agarose gels with TAE buffer ( $40 \mathrm{mM}$ Tris-acetate, $1 \mathrm{mM}$ EDTA [pH 8.5]) at 0.4 $\mathrm{V} / \mathrm{cm}$ for $48 \mathrm{~h}$. Fractionated DNA was transferred to GeneScreen membranes by use of the VacuGene vacuum blot system as instructed by the manufacturer (Pharmacia-LKB). The transferred DNA was fixed to the membranes by UV cross-linking with a Stratalinker (Stratagene) as instructed by the manufacturer. $o s p C$ hybridization probes were synthesized on the basis of the $\operatorname{cspC}$ sequence previously presented for the Lyme disease isolate PKo (11). Both Adam et al. (1) and Wallich et al. (28) have identified this isolate as belonging to the VS461 group of Lyme disease spirochetes. Oligonucleotide probe sequences are presented in Table 2. All sequences given in this paper are listed $5^{\prime} \rightarrow 3^{\prime}$. Oligonucleotide probes were $5^{\prime}$ end labeled with $\left[\gamma^{32}\right.$ P]ATP by use of polynucleotide kinase by standard methods. Radiolabeled probes were purified from unincorporated label by passage through G25 spin columns as instructed by the manufacturer (Boehringer Mannheim). The blots were pre- 
TABLE 1. Borrelia isolates used in this study

\begin{tabular}{|c|c|c|}
\hline Isolates & $\begin{array}{c}\text { Geographic } \\
\text { origin }\end{array}$ & Biological source ${ }^{a}$ \\
\hline \multicolumn{3}{|l|}{ Borrelia burgdorferi } \\
\hline 25015 & New York & Lxodes dammini \\
\hline Illinois 1 & Illinois & Mouse \\
\hline 1352 & Texas & Amblyomma americanum \\
\hline 20004 & France & Lxodes ricinus \\
\hline IP2A & France & Human CSF \\
\hline $\mathrm{CA} 12$ & California & Lxodes pacificus \\
\hline 3028 & Texas & Human pus \\
\hline \multicolumn{3}{|l|}{ Borrelia garinii } \\
\hline G25, VS102 & Sweden & Lxodes ricinus \\
\hline G1 & Germany & Human CSF \\
\hline R-IP90 & Russia & Lxodes persulcatus \\
\hline 20047 & France & Lxodes ricinus \\
\hline N34 & Germany & Lxodes ricinus \\
\hline \multicolumn{3}{|l|}{ VS461 group } \\
\hline U01, ECM1, UM01 & Sweden & EM (human) \\
\hline R-IP21, R-IP3 & Russia & Lxodes persulcatus \\
\hline VS461 & Sweden & Lxodes ricinus \\
\hline B023 & Germany & Human skin \\
\hline $\mathrm{J} 1$ & Japan & Lxodes persulcatus \\
\hline
\end{tabular}

${ }^{a}$ CSF, cerebrospinal fluid; EM, erythema migrans.

hybridized in hybridization buffer (16) for 1 to $4 \mathrm{~h}$ at $37^{\circ} \mathrm{C}$. After prehybridization, the buffer was removed and radioactive probes at $10 \mathrm{ng} / \mathrm{ml}$ in fresh hybridization buffer were added to the hybridization bottles. Hybridization was conducted for 16 to $24 \mathrm{~h}$ at $37^{\circ} \mathrm{C}$. The blots were washed twice in $2 \times \mathrm{SSC}(1 \times \mathrm{SSC}$ is $0.15 \mathrm{M} \mathrm{NaCl}$ plus $0.015 \mathrm{M}$ sodium citrate) $-0.1 \%$ sodium dodecyl sulfate (SDS) at $37^{\circ} \mathrm{C}(10 \mathrm{~min}$ each) and once for $1 \mathrm{~h}$ in $0.1 \times \mathrm{SSC}-0.1 \% \mathrm{SDS}$ at $37^{\circ} \mathrm{C}$, wrapped in cellophane, and exposed to Kodak XAR5 film at $-70^{\circ} \mathrm{C}$ with intensifying screens.

Two-dimensional agarose gel electrophoresis. For determination of the conformation of the DNA molecule carrying the ospC gene, two-dimensional gel electrophoresis was performed $(21,22)$. DNA from isolates R-IP21 and VS461 was electrophoresed in $0.35 \%$ agarose gels in the first dimension for $18 \mathrm{~h}$ at $0.4 \mathrm{~V} / \mathrm{cm}$ with TAE buffer. The gels were then equilibrated in second-dimension running buffer ( $15 \mu \mathrm{M}$ chloroquine in TAE buffer) by soaking for $5 \mathrm{~h}$. After the gels were rotated $90^{\circ}$ relative to the direction of electrophoresis in the first dimension, electrophoresis was performed for $18 \mathrm{~h}$ at $0.4 \mathrm{~V} / \mathrm{cm}$. Prior to ethidium bromide staining, the gels were soaked in $\mathrm{H}_{2} \mathrm{O}$ for several hours to remove the chloroquine. Fractionated DNA was transferred

TABLE 2. Oligonucleotide hybridization probe or primer sequences

\begin{tabular}{lll}
\hline $\begin{array}{c}\text { Probe or } \\
\text { primer }\end{array}$ & \multicolumn{1}{c}{ Sequence $\left(5^{\prime} \rightarrow 3^{\prime}\right)^{a}$} & \multicolumn{1}{c}{$\begin{array}{c}\text { Target } \\
\text { region }^{b}\end{array}$} \\
\hline pC13 & GTC-ATT-AAT-ATC-GCA-CTT-AAT-G & 13 to 35 \\
pC52 & CCC-TGA-ATT-ATT-ACA-AGA & 52 to 66 \\
pC67 & TGC-AGA-ATC-CCC-ACC-TTT-CCC & 67 to 87 \\
pC609 & TGG-ACT-TTC-TGC-TAC-AAC-AGG & 609 to 629 \\
nc20 & ATG-AAT-TAT-AGT-CCA-ACA-AT & -40 to -20 \\
\hline
\end{tabular}

${ }^{a}$ All probes or primers complement the coding (plus) strand.

${ }_{b}$ The numbers given are relative to the translational start codon of the ospC sequence previously presented for VS461 group isolate PKo (11). to GeneScreen membranes for hybridization analysis with ospC oligonucleotide probes as described above.

Transcriptional start site and Northern blot analyses. Total cellular RNA was isolated as previously described (25). All reagents were either prepared with diethylpyrocarbonatetreated $\mathrm{H}_{2} \mathrm{O}$ or treated directly with diethylpyrocarbonate by standard methods. The transcriptional start site(s) for the ospC gene was determined by reverse transcriptase primer extension. Fifteen micrograms of total cellular RNA was incubated with 2 pmol of 5'-end-labeled primer pC13, pC52, pC67, or nc20 in $10 \mu \mathrm{l}$ of annealing buffer $(100 \mathrm{mM} \mathrm{KCl}, 5$ $\mathrm{mM}$ Tris- $\mathrm{HCl}$ [pH 7.5]) at $85^{\circ} \mathrm{C}$ for $4 \mathrm{~min}$ and then at $30^{\circ} \mathrm{C}$ for 4 to $6 \mathrm{~h}$. Fifteen microliters of reverse transcription mixture (0.9 mM each dATP, dTTP, dCTP, and dGTP; $83 \mathrm{mM}$ Tris- $\mathrm{HCl}$ [pH 8.3]; $8 \mathrm{mM}$ dithiothreitol; $8 \mathrm{mM} \mathrm{MgCl}_{2} ; 83 \mu \mathrm{g}$ of bovine serum albumin per $\mathrm{ml}$ ) and $50 \mathrm{U}$ of avian myeloblastosis virus reverse transcriptase were added, and the reaction mixtures were incubated for $1.5 \mathrm{~h}$ at $47^{\circ} \mathrm{C}$. For digestion of the RNA, $1 \mu$ l of $0.5 \mathrm{M}$ EDTA and $1 \mu$ l of RNase $(0.5 \mu \mathrm{g} / \mu \mathrm{l})$ were added and the mixture was incubated for 0.5 $h$ at $37^{\circ} \mathrm{C}$. One volume of $2.5 \mathrm{M}$ ammonium acetate was added to each tube, and each was extracted with an equal volume of phenol-chloroform-isoamyl alcohol. The extension products were precipitated with ethanol, washed with $70 \%$ ethanol, vacuum dried, resuspended in $10 \mu \mathrm{l}$ of formamide loading buffer ( $50 \%$ formamide, $10 \mathrm{mM}$ EDTA, $0.025 \%$ bromophenol blue, $0.025 \%$ xylene cyanol), heated at $85^{\circ} \mathrm{C}$ for $5 \mathrm{~min}$, and loaded onto $7 \%$ polyacrylamide sequencing gels (8 M urea, $83 \mathrm{mM}$ Tris-borate, $1 \mathrm{mM}$ EDTA [pH 8.0]). The approximate sizes of the extension products were determined by use of a DNA sequencing ladder. After electrophoresis, the gels were transferred directly to $3 \mathrm{MM}$ paper (Whatman) and exposed to Kodak XAR5 film for $3 \mathrm{~h}$.

Northern blot analysis was used to assess the expression of the $o s p C$ gene and to determine the nucleotide length of the transcript. Fifteen micrograms of RNA sample was electrophoresed through $1.2 \%$ agarose-formaldehyde gels as previously described (27). The RNA was transferred to GeneScreen membranes and hybridized as described above for the Southern blot analysis. The length of the ospC transcript was determined by use of an NA2 nucleic acid analyzer as instructed by the manufacturer (Bethesda Research Laboratories).

\section{RESULTS AND DISCUSSION}

Mapping of the ospC gene to a circular plasmid. In this study, we sought to map the $\operatorname{osp} C$ locus in a variety of isolates of each of the three Lyme disease-associated spirochete species $(2,9,15-17,19,20,29)$. Total DNA from the isolates listed in Table 1 was isolated and fractionated in $0.35 \%$ agarose gels. After Southern transfer, the blots were probed with an ospC oligonucleotide probe (pC13). Two or three hybridization bands that differed in intensity and relative ratio among isolates were observed. The ethidium bromide-stained gel and the corresponding Southern blot of representative isolates are presented in Fig. 1 . The detection of more than one band suggested that the probe was either hybridizing with an $\operatorname{sspC}$ gene carried on multiple DNA species or cross-hybridizing with non-ospC but closely related sequences. To differentiate between these possibilities, we used a second probe (pC609), which complements a region in the $3^{\prime}$ end of the $\operatorname{osp} C$ gene, to rescreen some of the blots. This probe hybridized with the same bands as the pC13 probe. A third probe (pC67) also yielded identical hybridization results. Both the pC67 and the pC609 probes, 


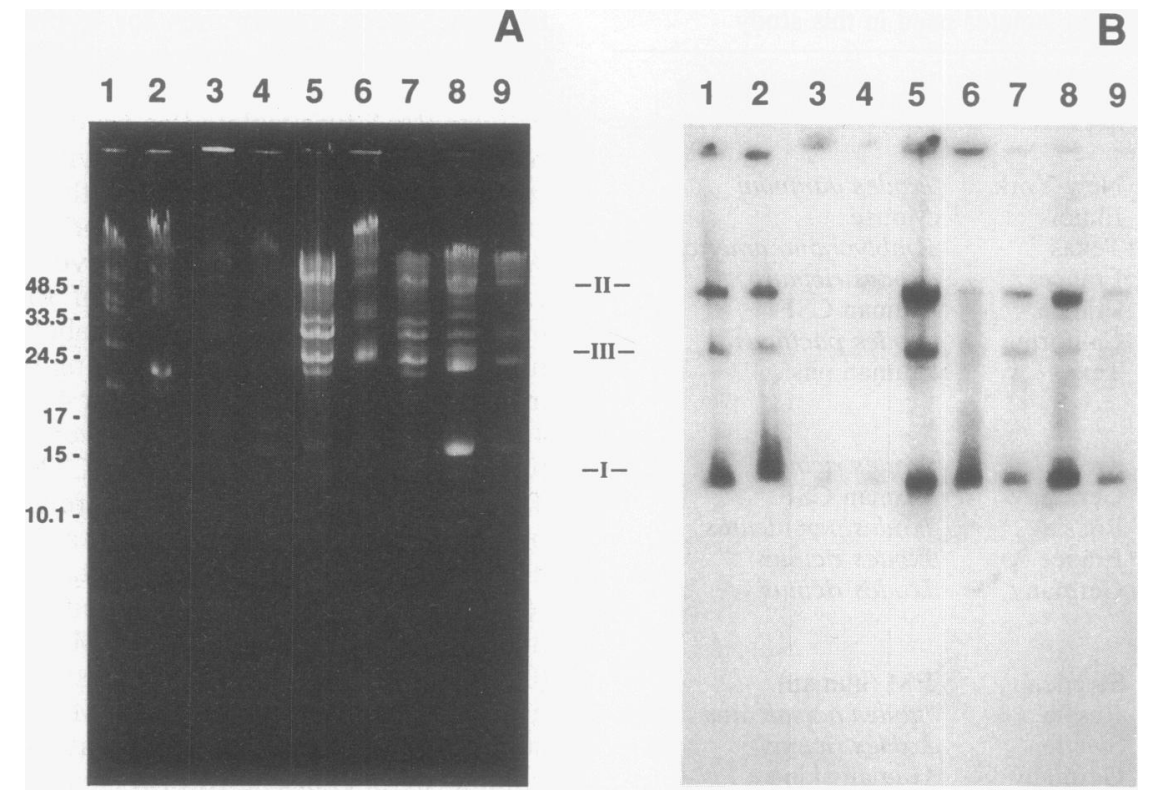

FIG. 1. Agarose gel fractionation of Lyme disease spirochete DNA and Southern blot analysis of the ospC gene. Total DNA isolated from the three Lyme disease-associated organisms was fractionated in $0.35 \%$ agarose gels, stained with ethidium bromide (A), transferred to GeneScreen membranes, and probed with the $\mathrm{pC} 13$ probe $(\mathrm{B})$ as described in the text. DNA from the following respective isolates was analyzed: lanes 1 and 2, B. garinii VS102 and R-IP90; lanes 3 and 4, B. burgdorferi 20004 and IP2A; and lanes 5 to 9, VS461 group isolates R-IP21, VS461, R-IP3, ECM1, and UM01. DNA molecular size markers are given in kilobases. The three plasmid forms are indicated by I (supercoiled), II (relaxed), and III (linearized).

however, did not hybridize with the $o s p C$ gene in all isolates, suggesting sequence variability in this gene (see below). Nonetheless, the use of multiple probes, all of which hybridized with the same DNA bands, demonstrates that the multiple hybridization signals observed were due to the detection of multiple $\operatorname{ssp} C$-carrying DNA molecules.

The detection of multiple hybridizing bands and their relative migration rates in agarose gels suggested that the gene may be carried on a circular plasmid. Circular plasmids can be found in three distinct conformational states. Form I is the supercoiled form. Form II consists of relaxed molecules that comigrate with supercoiled plasmids that have been nicked. Form III represents plasmids that have been linearized by a double-strand break. The hybridization pattern suggested a circular plasmid of $26 \mathrm{~kb}$, with the supercoiled form (I) migrating with an apparent size of $12 \mathrm{~kb}$ and the nicked or relaxed form (II) migrating with an apparent size of $44 \mathrm{~kb}$ (Fig. 1B). Furthermore, upon restriction of the DNA from several isolates with EcoRV, Southern blotting, and probing with the pC67 probe, only one hybridization band was observed (data not shown). These results further support the idea that one copy of the $\operatorname{osp} C$ gene was present and being carried on different conformational forms of the same plasmid.

While the detection of multiple hybridizing bands in undigested DNA preparations is highly suggestive of a circular plasmid, we further addressed this question by using two-dimensional gel electrophoresis. Linear and circular plasmids, which cannot be distinguished from each other by conventional agarose gel electrophoresis, can be conclusively differentiated via this approach. For these analyses, new DNA preparations were gently isolated (i.e., vortexing and pipetting were minimized during isolation) from VS461 group isolates R-IP21 and VS461 to reduce shear damage to the circular plasmids in the DNA preparations. After stan- dard electrophoresis of the DNA in the first dimension, the gels were equilibrated in chloroquine. Chloroquine intercalates into the DNA, causing an unwinding of the double helix. The electrophoretic mobility of linear molecules is not significantly affected by chloroquine treatment. These molecules migrate along an apparent diagonal axis in twodimensional chloroquine gels. However, the electrophoretic mobility of negatively supercoiled plasmids is retarded by chloroquine treatment and, as a result, these plasmids migrate off the diagonal axis during electrophoresis in the second dimension (22). Three DNA species were found in ethidium bromide-stained gels to migrate off the diagonal axis, indicating that these molecules were covalently closed and negatively supercoiled (Fig. 2A). The gels were then blotted and subjected to Southern blot analysis with the pC67 hybridization probe. A hybridization signal was detected associated with one of the molecules running off the diagonal axis (Fig. 2B), demonstrating that the ospC gene is carried on a single negatively supercoiled plasmid. In contrast to the results of the Southern blot analysis described above, only one band was found to hybridize with the probe. Hence, the elimination of vortexing from the DNA isolation procedure significantly reduced shearing of the circular plasmids and, as a result, only the supercoiled form of the ospC-carrying plasmid was observed. The size of the circular plasmid was obtained by measuring the linearized form (Fig. 1) and found to be $26 \mathrm{~kb}$.

Occurrence and conservation of the ospC gene in Lyme disease spirochetes. Wilske et al. have reported that OspC is expressed in $45 \%$ of European isolates and only rarely in North American isolates (31). To evaluate the occurrence of the $\operatorname{sspC}$ gene, we performed Southern blotting of undigested whole-cell DNA from a variety of isolates of the three spirochete species associated with Lyme disease. The results obtained with representative isolates are presented in 

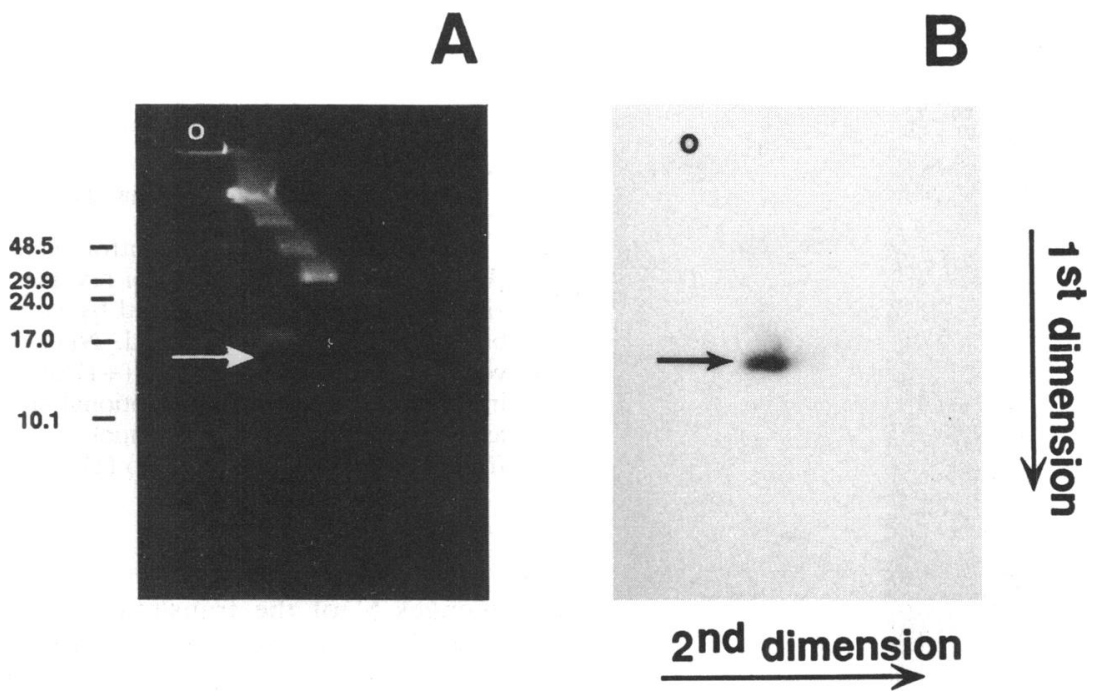

FIG. 2. Two-dimensional gel electrophoresis of DNA from Lyme disease isolate VS461 and Southern blot analysis with the pC67 probe. Electrophoresis of DNA from isolate VS461 was conducted in the first dimension in $0.35 \%$ agarose gels. The gels were then equilibrated in $15 \mu \mathrm{M}$ chloroquine, rotated $90^{\circ}$, and electrophoresed in the second dimension as described in the text. The DNA was visualized by ethidium bromide staining $(\mathrm{A})$ and then transferred to GeneScreen membranes for Southern blotting as described in the text with the radiolabeled pC67 oligonucleotide probe (B). In both panels, the position of the loading well is indicated by a circle, and that of the 26-kb plasmid is indicated by an arrow. The direction of migration in each dimension is also given. DNA molecular size markers are given in kilobases.

Fig. 1. Detection of the $o s p C$ gene in a given isolate was found to be dependent on the probe used. While the pC609 probe was found to exhibit differential hybridization with different isolates, this probe was not used to screen all isolates and hence will not be discussed further. Most $B$. burgdorferi isolates and $B$. garinii G1 and R-IP90 were hybridization negative with the $\mathrm{pC} 67$ probe but hybridization positive with the pC13 probe. B. burgdorferi 25015 and Illinois 1 were exceptions in that they hybridized with both the pC67 and the $\mathrm{pC} 13$ probes. We have demonstrated the peripheral relationship of these isolates to others of $B$. burgdorferi via $16 \mathrm{~S}$ rRNA sequence analysis (15). In contrast to $B$. garinii R-IP90 and G1, VS461 group isolates and $B$. garinii G25, 20047, and VS102 were hybridization positive with both the $\mathrm{pC} 13$ and the $\mathrm{pC} 67$ probes. Hence, while the phenotypic expression of the ospC gene appears most pronounced in European isolates, the ospC gene itself is present in all three Lyme disease-associated spirochete species. Furthermore, it consistently maps to an approximately $26-\mathrm{kb}$ circular plasmid in all isolates tested. The variability in hybridization among isolates indicates that the ospC gene sequence may be somewhat variable. A similar variability has been noted for outer surface protein genes osp $A$ and $\operatorname{ospB}(7,13,18,30)$.

Northern blot analysis of the osp $C$ transcript. To determine in which isolates the $o s p C$ gene was being transcriptionally expressed, we performed Northern blot analysis with the pC13 and pC67 hybridization probes. Consistent with the Southern blot analysis discussed above, the detection of the $o s p C$ transcript in a given isolate was dependent on the probe used. ospC transcript size was constant among isolates, being approximately 700 to 730 nucleotides (Fig. 3). The ospC coding sequence alone (excluding $5^{\prime}$ and $3^{\prime}$ noncoding sequences) would generate a 636-base transcript. While the $\operatorname{ospC}$ gene was detected by Southern blot analysis in all isolates with either the $\mathrm{pC} 13$ or the $\mathrm{pC} 67$ probe, we did not detect the transcript in several isolates by Northern blot analysis with these same probes. $B$. burgdorferi CA12 and
1352, B. garinii N34, and VS461 group isolates J1, R-IP21, and UM01 were all found to carry the $\operatorname{csp} C$ gene but not to express it under the growth conditions used in these experiments. The rRNA bands in the hybridization-negative preparations were found to show good integrity via ethidium bromide staining, providing indirect evidence that the lack of hybridization was not the result of template degradation. Furthermore, using these same RNA preparations, we were able to detect the osp $A B$ transcript. Factors associated with the transcriptional activation of the $\operatorname{osp} C$ gene have not yet been defined. In addition, several VS461 group isolates that produced the ospC transcript did not exhibit detectable amounts of OspC protein, as determined by inspection of Coomassie-stained sodium dodecyl sulfate-polyacrylamide gel electrophoresis whole-cell protein profiles (data not

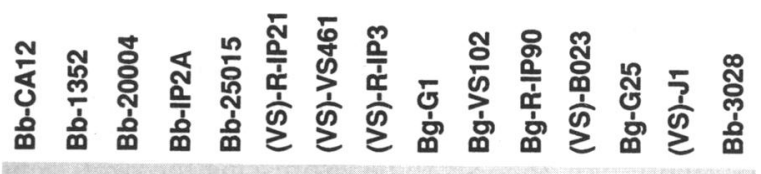

23S -

16S -

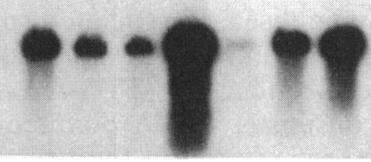

FIG. 3. Detection of the $o s p C$ transcript by Northern blot analysis. Fifteen micrograms of total cellular RNA was fractionated in $1.2 \%$ agarose-formaldehyde gels, vacuum blotted onto GeneScreen membranes, and hybridized with the $\mathrm{pC13}$ probe as described in the text. The species designation for each isolate is indicated by the prefixes $\mathrm{Bb}$ for $\boldsymbol{B}$. burgdorferi, $\mathrm{Bg}$ for $\boldsymbol{B}$. garinii, and (VS) for VS461 group isolates. The positions of $23 \mathrm{~S}$ and $16 \mathrm{~S}$ rRNAs (approximately 2,900 and 1,540 bases, respectively) are indicated. 


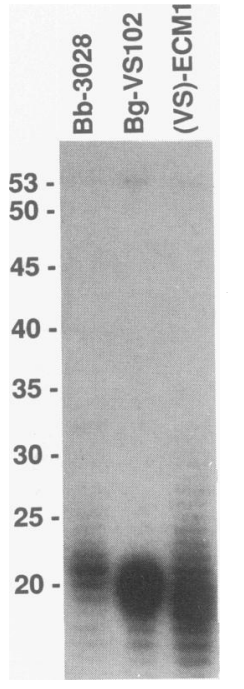

FIG. 4. Transcriptional start site analyses by reverse transcriptase primer extension. All methods were as described in the text. The pC52 primer was used in the primer extension reactions. The lanes (left to right) contain the extension products obtained when total RNAs $(15 \mu \mathrm{g})$ from B. burgdorferi 3028, B. garini VS102, and VS461 group isolate ECM1, respectively, were used as templates. The numbers on the left indicate the approximate number of bases $5^{\prime}$ of the translational start codon for each major primer extension termination site, as determined by electrophoresis of a sequencing ladder in adjacent lanes.

shown). OspC expression in these isolates may be subject to some form of translational control. Alternatively, there may be mutations in the gene that result in premature translational termination. It has been demonstrated that the phenotypic expression of the osp $A$ and $o s p B$ genes in some isolates can be influenced by the number of in vitro passages (24). While in this study we did not systematically monitor OspC expression over a large number of passages in a given isolate, isolates of both high and low passage numbers were used. No correlation between passage number and OspC expression was observed.

Transcriptional start site analyses of the ospC gene. To identify the putative promoter(s) of the ospC gene, we performed transcriptional start site analyses by using reverse transcriptase primer extension. By using two independent primers (pC13 and $\mathrm{pC52}$ ), the same primer extension termination sites were observed in all isolates which had been by Northern blot analysis to be expressing the ospC gene. The major termination sites mapped approximately 18 to 22 nucleotides upstream from the translational start codon. The results obtained with a representative isolate of each of the three Lyme disease-associated species and the pC52 primer are presented in Fig. 4. An appropriately spaced consensus promoter sequence $\left(5^{\prime}\right.$-TTG-AAA-A) that we refer to as P1 and a consensus TATA box sequence (5'-TATTAA) were identified upstream (on the basis of the ospC sequence for isolate $\mathrm{PKo}$ ) (Fig. 5). Hence, the transcripts derived from the use of promoter P1 possess a 5'-untranslated leader sequence of approximately 20 nucleotides, with the $T$ residue located 20 bases from the translational start codon serving as the major transcriptional start site (TS1). Using the RNA secondary structure analysis program of Zucker (contained in the PCGENE software package) (32), we analyzed se-

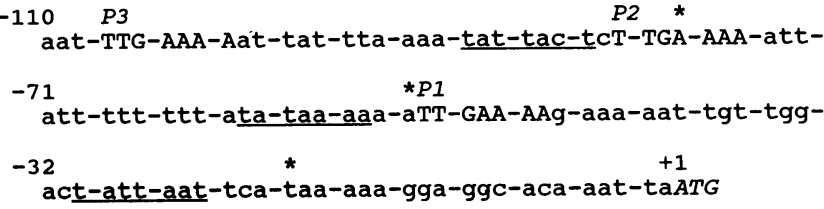

FIG. 5. Putative ospC control regions. -35 promoter regions (P1, P2, and P3) inferred from reverse transcriptase primer extension experiments are indicated by capital letters, and -10 TATA box sequences are underlined. Nucleotide position numbering is with respect to the first base $(+1)$ of the translational start codon indicated by italics. Transcriptional start sites are indicated by an asterisk over the appropriate nucleotide. The sequence presented is from VS461 group isolate PKo (11).

quences $5^{\prime}$ of the translational start codon for regions of secondary structure that could conceivably be responsible for the termination sites observed in the primer extension analysis. However, significant secondary structure elements were not observed, supporting the identification of TS1 as the major transcriptional start site.

Through a consensus promoter sequence homology search, Fuchs et al. (11) identified a putative promoter upstream of P1 that we refer to as P2. This sequence is not optimally spaced to serve as the promoter for TS1. However, when both the $\mathrm{pC} 13$ and the pC52 primers were used, a second transcriptional start site (TS2) was observed upstream of the TS1 site, implicating active transcription from a promoter $5^{\prime}$ of $\mathrm{P} 1$ (Fig. 4). In B. burgdorferi 3028, a minor extension product intermediate in size in comparison with those derived from P1 and P2 was observed. The sequence of this product is not appropriately spaced from a consensus promoter sequence, so this product most likely represents a premature termination product. P2 appears appropriately spaced from TS2 to serve as a promoter for this transcriptional start site. Visualization of the band corresponding to TS2 required a longer exposure of the separating gel to film (approximately 6 to $10 \mathrm{~h}$ ) than that required for the detection of TS1. The exposure presented in Fig. 4 was chosen since it allowed visualization of both transcriptional start sites without overexposure of TS1. Both P1 and P2 are identical in sequence over a 7-base stretch (5'-TTG-AAA-A) and have appropriately spaced -10 sequences (Fig. 5): The core sequences of $\mathrm{P} 1$ and $\mathrm{P} 2$ and their respective -10 sequences are separated by 15 and 13 bases, respectively. While transcriptional start sites were observed appropriately spaced from both $\mathrm{P} 1$ and $\mathrm{P} 2$, it is possible that only the more distal promoter, P2, was used and that the shorter transcript was the result of an RNA processing event. While the data presented here are suggestive of active transcription from more than one promoter, RNA processing cannot be ruled out.

Upon analysis of the PKo ospC sequence (11), we noted a third potential promoter sequence (P3) upstream of and identical to the 7-base core sequences of P1 and P2. Over a 16-base stretch, $\mathrm{P} 3$ exhibits $88 \%$ sequence similarity to $\mathrm{P} 2$. To determine whether this putative promoter sequence was transcriptionally active, we used a third primer (nc20) in the primer extension analysis. This primer complements a sequence in the $\operatorname{osp} C$ gene $5^{\prime}$ of TS1. While the $5^{\prime}$ end of this 20-base primer complements the first 6 nucleotides of transcripts derived from the expression of promoter P2, these transcripts should not serve as a template for primer extension, since the $3^{\prime}$ end of this primer does not hybridize. 
Hence, any extension products should be derived from hybridization with a transcript that uses a more distal $5^{\prime}$ promoter. In two isolates $(B$. burgdorferi 3028 and B. garinii VS102), a weak transcription start site, not previously observed when primers pC13 and pC52 were used, was detected (data not shown). Hence, promoter P3 may be used at a low level in the transcription of the $o s p C$ gene in some isolates. The low level of transcription from this promoter may be a reflection of the spacing between the -35 and -10 sequences (11 bases). None of the three transcriptional start sites described above was observed in isolate R-IP21, which was shown not to produce the $\operatorname{se} p C$ transcript by Northern blot analysis, demonstrating that the start sites detected were not the result of spurious or nonspecific primer extension from non-ospC transcripts. The role of each promoter, the extent to which each is used, and the factors influencing promoter selection in vivo are currently undefined.

The ospC gene represents the first Borrelia gene to be mapped on a circular plasmid. The plasmid is approximately $26 \mathrm{~kb}$ in size. On the basis of hybridization results with a variety of oligonucleotide probes, this gene appears to exhibit some variability in its coding sequence among the Lyme disease isolates tested. The organization of the upstream regulatory regions, however, appears similar among isolates with a potential multiple-promoter arrangement. The results presented here may provide further insight into the genetic coding capacity of the plasmids found in Lyme disease isolates. Since the plasmids represent approximately $150 \mathrm{~kb}$ of genetic material, it is likely that additional genes will be localized on plasmids and shown to encode products that may be important in the pathobiology of Lyme disease.

\section{ACKNOWLEDGMENTS}

We thank J. Anderson, G. Baranton, A. Barbour, S. Barthold, J. Nelson, O. Peter, D. Postic, J. Rawlings, P. Rosa, and T. Schwan for providing isolates; J. Heinemann and J. Hinnebusch for helpful discussions and critical review of the manuscript; and R. Evans and G. Hettrick for providing the graphic work.

\section{REFERENCES}

1. Adam, T., G. S. Gassmann, C. Rasiah, and U. B. Göbel. 1991. Phenotypic and genotypic analysis of Borrelia burgdorferi isolates from various sources. Infect. Immun. 59:2579-2585.

2. Baranton, G., D. Postic, I. Saint Girons, P. Boerlin, J.-C. Piffaretti, M. Assous, and P. A. D. Grimont. 1992. Delineation of Borrelia burgdorferi sensu stricto, Borrelia garinii sp. nov., and group VS461 associated with Lyme borreliosis. Int. J. Syst. Bacteriol. 42:378-383.

3. Barbour, A. G. 1984. Isolation and cultivation of Lyme disease spirochetes. Yale J. Biol. Med. 57:521-525.

4. Barbour, A. G. 1988. Plasmid analysis of Borrelia burgdorferi, the Lyme disease agent. J. Clin. Microbiol. 26:475-478.

5. Barbour, A. G., and C. F. Garon. 1987. Linear plasmids of the bacterium Borrelia burgdorferi have covalently closed ends. Science 237:409-411.

6. Barbour, A. G., and C. F. Garon. 1988. The genes encoding major surface proteins of Borrelia burgdorferi are located on a plasmid. Ann. N.Y. Acad. Sci. 539:144-153.

7. Barbour, A. G., R. A. Heiland, and T. R. Howe. 1985. Heterogeneity of major proteins in Lyme disease borreliae: a molecular analysis of North American and European isolates. J. Infect. Dis. 152:478- 484 .

8. Bergström, S., V. G. Bundoc, and A. G. Barbour. 1989. Molecular analysis of the linear plasmid encoded major surface proteins, OspA and OspB, of the Lyme disease spirochaete
Borrelia burgdorferi. Mol. Microbiol. 3:479-486.

9. Boerlin, P., O. Peter, A.-G. Bretz, D. Postic, G. Baranton, and J.-C. Piffaretti. 1992. Population genetic analysis of Borrelia burgdorferi isolates by multilocus enzyme electrophoresis. Infect. Immun. 60:1677-1683.

10. Ferdows, M. S., and A. G. Barbour. 1989. Megabase-sized linear DNA in the bacterium Borrelia burgdorferi, the Lyme disease agent. Proc. Natl. Acad. Sci. USA 86:5969-5973.

11. Fuchs, R., S. Jauris, F. Lottspeich, V. Preac-Mursic, B. Wilske, and E. Soutschek. 1992. Molecular analysis and expression of a Borrelia burgdorferi gene encoding a $22 \mathrm{kDa}$ protein $(\mathrm{pC})$ in Escherichia coli. Mol. Microbiol. 6:503-509.

12. Gassman, G. S., M. Kramer, U. B. Göbel, and R. Wallich. 1989. Nucleotide sequence of the gene encoding the Borrelia burgdorferi flagellin. Nucleic Acids Res. 17:3590.

13. Jonsson, M., L. Noppa, A. G. Barbour, and S. Bergström. 1992. Heterogeneity of outer membrane proteins in Borrelia burgdorferi: comparison of osp operons of three isolates of different geographic origins. Infect. Immun. 60:1845-1853.

14. Luft, B. J., W. Jiang, P. Munoz, R. J. Dattwyler, and P. D. Gorevic. 1989. Biochemical and immunological characterization of the surface proteins of Borrelia burgdorferi. Infect. Immun. 57:3637-3645.

15. Marconi, R. T., and C. F. Garon. 1992. Development of polymerase chain reaction primer sets for diagnosis of Lyme disease and for species-specific identification of Lyme disease isolates by $16 \mathrm{~S}$ rRNA signature nucleotide analysis. J. Clin. Microbiol. 30:2830-2834.

16. Marconi, R. T., and C. F. Garon. 1992. Phylogenetic analysis of the genus Borrelia: a comparison of North American and European isolates of Borrelia burgdorferi. J. Bacteriol. 174:241244.

17. Marconi, R. T., and C. F. Garon. 1992. Identification of a third genomic group of Borrelia burgdorferi through signature nucleotide analysis and 16S rRNA sequence determination. J. Gen. Microbiol. 138:533-536.

18. Marconi, R. T., M. E. Konkel, and C. F. Garon. Submitted for publication.

19. Marconi, R. T., L. Lubke, W. Hauglum, and C. F. Garon. 1992. Species-specific identification of and distinction between Borrelia burgdorferi genomic groups by using 16S rRNAdirected oligonucleotide probes. J. Clin. Microbiol. 30:628632.

20. Postic, D., C. Edlinger, C. Richaud, F. Grimont, Y. Dufresne, P. Perolat, G. Baranton, and P. A. D. Grimont. 1990. Two genomic species in Borrelia burgdorferi. Res. Microbiol. 141:465-475.

21. Pruss, G. J. 1985. DNA topoisomerase I mutants: increased heterogeneity in linking number and other replicon-dependent changes in DNA supercoiling. J. Mol. Biol. 185:51-63.

22. Samuels, D. S., and C. F. Garon. 1993. Coumermycin $A_{1}$ inhibits growth and induces relaxation of supercoiled plasmids in Borrelia burgdorferi, the Lyme disease agent. Antimicrob. Agents Chemother. 37:46-50.

23. Samuels, D. S., R. T. Marconi, and C. F. Garon. Submitted for publication.

24. Schwan, T. G., W. Burgdorfer, and C. F. Garon. 1988. Changes in infectivity and plasmid profile of the Lyme disease spirochete, Borrelia burgdorferi, as a result of in vitro cultivation. Infect. Immun. 56:1831-1836.

25. Selden, R. F. 1991. Preparation and analysis of RNA, p. 4.4.4-4.4.6. In F. M. Ausubel, R. Brent, R. E. Kingston, D. D. Moore, J. G. Seidman, J. A. Smith, and K. Struhl (ed.), Current protocols in molecular biology. Greene Publishing Associates and Wiley-Interscience, New York.

26. Simpson, W. J., W. Burgdorfer, M. E. Schrumpf, R. H. Karstens, and T. G. Schwan. 1991. Molecular and immunological analysis of a polymorphic periplasmic protein of Borrelia burgdorferi. J. Clin. Microbiol. 29:1940-1948.

27. Thomas, P. S. 1980. Hybridization of denatured RNA and small DNA fragments transferred to nitrocellulose. Proc. Natl. Acad. Sci. USA 77:5201-5205.

28. Wallich, R., C. Helmes, U. E. Schaible, Y. Lobet, S. E. Moter, M. D. Kramer, and M. M. Simon. 1992. Evaluation of genetic 
divergence among Borrelia burgdorferi isolates using OspA, fla, HSP60, and HSP70 gene probes. Infect. Immun. 60:4856-4866.

29. Welsh, J., C. Pretzman, D. Postic, I. Saint Girons, G. Baranton, and M. McClelland. 1992. Genomic fingerprinting by arbitrarily primed polymerase chain reaction resolves Borrelia bungdorferi into three distinct phyletic groups. Int. J. Syst. Bacteriol. 42:370-377.

30. Wilske, B., V. Preac-Mursic, G. Schierz, and K. V. Busch. 1986.
Immunochemical and immunological analysis of European Borrelia burgdorferi strains. Zentralbl. Bakteriol. Mikrobiol. Hyg. Ser. A 263:92-102.

31. Wilske, B., V. Preac-Mursic, G. Schierz, R. Kuhbeck, A. G. Barbour, and M. Kramer. 1988. Antigenic variability of Borrelia burgdorferi. Ann. N.Y. Acad. Sci. 539:126-143.

32. Zucker, M., and P. Stiegler. 1981. Description of the method used in RNAFOLD. Nucleic Acids Res. 9:133-148. 